\title{
IMPACT OF PHYSICAL ACTIVITY AND COOKING OIL AMONGST DIABETES WITH COEXISTING HYPERTENSION PATIENTS ON ECONOMIC COST AND LENGTH OF STAY: A 1914 PATIENTS OBSERVATIONAL STUDY
}

\author{
Amit Sharma $^{1}$, Ashish Baldi ${ }^{2}$, and Dinesh Kumar Sharma ${ }^{3}$ \\ ${ }^{1}$ ISF College of Pharmacy \\ ${ }^{2}$ Maharaja Ranjit Singh Punjab Technical University \\ ${ }^{3}$ Himalayan Institute of Pharmacy and Research
}

January 2, 2021

\begin{abstract}
Background: Diabetes mellitus with coexisting hypertension contributes to increased morbidity and mortality. The study aimed to investigate the impact of the patients' physical activity status and the type of cooking oil consumed by patients in their daily routine on glycemic profile, lipid profile, the hypertensive profile of the patients, and the length of stay, and overall cost of the treatment. Methods: A prospective observational study. All the patients referred to the medicine department of the three different hospitals located in Moga, City Punjab and those hospitalized due to diabetes mellitus (type-I and type-II) with coexisting hypertension were asked to participate in the study. Results: The patients' mean age was found to be $\mathrm{M}=53.85$, $\mathrm{SD}=11.54$ years. Out of 1914 patients, 914 were male (47.8\%); it was observed that the majority of the patients $525(27.43 \%)$ in North India using butter or ghee- clarified butter as edible oil, followed by mustard oil 517 (27.01\%) patients. About 345 (18.03\%) of the patients consume soybean oil, whereas $226(11.81 \%)$ of the patients like sunflower oil. Discussion: This study explored that cooking oil and physical activity are associated with length of stay in days \& overall cost of the treatment, respectively. Our study results revealed that the type of oil compared with the treatment's overall cost was significant for olive oil, soybean oil, and groundnut oil. Conclusion: The study revealed that moderate and low physical activity increases the length of stay compared to high physical activity. The consumption of olive oil as a regular food habit in daily routine decreases patients' length of stay with diabetes with coexisting hypertension when doing the high physical activity but increases the overall cost of treatment.
\end{abstract}

\section{Hosted file}

Manuscript.pdf available at https://authorea.com/users/243463/articles/502144-impactof-physical-activity-and-cooking-oil-amongst-diabetes-with-coexisting-hypertensionpatients-on-economic-cost-and-length-of-stay-a-1914-patients-observational-study

\section{Hosted file}

Tables.pdf available at https://authorea.com/users/243463/articles/502144-impact-ofphysical-activity-and-cooking-oil-amongst-diabetes-with-coexisting-hypertensionpatients-on-economic-cost-and-length-of-stay-a-1914-patients-observational-study

\section{Hosted file}

Figures.pdf available at https://authorea.com/users/243463/articles/502144-impact-of- 
physical-activity-and-cooking-oil-amongst-diabetes-with-coexisting-hypertensionpatients-on-economic-cost-and-length-of-stay-a-1914-patients-observational-study 